DOI: $10.2478 / \mathrm{v} 10047-008-0005-7$

PHYSICAL AND TECHNICAL PROBLEMS OF ENERGETICS

\title{
COMPARISON OF DIFFERENT MODULATION FORMATS AND THEIR COMPATIBILITY WITH WDM TRANSMISSION SYSTEM
}

\author{
V. Bobrovs, G. Ivanovs \\ Institute of Telecommunications, Riga Technical University, \\ Âzenes ielā 12, Rīga, LV-1048, LATVIA
}

\begin{abstract}
In the work, the intensity and phase modulation methods are compared for different versions of the wavelength division multiplexing (WDM) system. Binary and multilevel code formats are evaluated numerically, with OptSim simulation software at the bit rate of 10 and $40 \mathrm{Gbit} / \mathrm{s}$, using long-fiber spans and dispersion compensation technique. The problems to be overcome at exploitation of multiterabit WDM systems based on $40 \mathrm{Gbit} / \mathrm{s}$ optical transmissions are: chromatic dispersion (CD), polarization-mode dispersion (PMD), dispersion slope, and nonlinear effects of the transmission line. We have investigated the potentialities of modulation formats for $40 \mathrm{Gbit} / \mathrm{s}$ WDM networks where most of the listed problems are avoided. It is shown that Duobinary and differential phase shift keying (DPSK) modulation formats are perfectly suitable for ultra-high spectral efficient WDM systems and possess high resistance to dispersion and nonlinear optical effects (NOE).
\end{abstract}

Key words: wavelength-division multiplexing (WDM), non-return-tozero (NRZ), return-to-zero (RZ), Duobinary, differential phase shift key (DPSK), nonlinear optical effects (NOE).

\section{INTRODUCTION}

Owing to the rapidly growing capacity requirements for long distance transmission, fiber optic telecommunications are advancing into high data rate enabled by wavelength division multiplexing (WDM). In order to maximize the system capacity and to minimize the performance degradation caused by transmission impairments the system investigation and optimization are important [1]. As in other telecommunication systems, the signal modulation method and code format are the key issues that determine the transmission quality and spectral efficiency.

In fiber optical transmission systems, the degradation effects can be categorized by the random noise and waveform distortion. For long-span WDM systems, signal waveform distortion can be generated by linear chromatic dispersion, fiber nonlinearity, or their combination. In high-speed time division multiplexing (TDM) optical systems, because of the short optical pulses and wide optical spectrum, the effect of chromatic dispersion dominates in the system performance. In multi-wavelength WDM optical systems the inter-channel crosstalk originated by fiber nonlinearity, such as cross-phase modulation (XPM) and fourwave mixing (FWM), is a limiting factor [2]. 
With the increasing transmission distance, a larger number of optical amplifiers have to be used, which generate more optical noise. To ensure a suitable signal-to-noise ratio (SNR), a higher signal optical power is needed, which leads to a strong crosstalk through the fiber nonlinear effect. Similarly, with the increasing data rate in each wavelength channel the optical spectral width also increases, which makes the system more susceptible to chromatic dispersion. The increased data rate also requires a larger electrical bandwidth for the receiver, which degrades its SNR. To maximize the WDM network capacity, the system's design and optimization have to take into account all the contributing factors - the channel data rate, the transmission distance, the signal optical power, the amplifier noise figure, the channel wavelength spacing, the fiber dispersion and the nonlinearity [1]. One of the most important factors in a system which affects the choice of all its other parameters is the signal optical modulation format. In fact, the signal optical spectral bandwidth, the tolerance to chromatic dispersion, the resistance to nonlinear crosstalk, and other system performance parameters are directly related to the optical modulation method and code format.

For a long time, the non-return-to-zero (NRZ) with on-off key (OOK) has been the dominant optical code format in the intensity modulation direct detection (IMDD) fiber optic systems. Recent research into different optical modulation formats was motivated by the demand for high transmission capacity, better system reliability and optimum operation [3]. Based on the information theory, in telecommunication systems and networks a variety of signal modulation formats have been studied extensively. In comparison with cable transmission and wireless communication systems, a fiber optic system possesses its unique properties, having however different sources of system performance degradation. Although there is no universal modulation format that would be immune to all sources of performance degradation, an accurate selection of the advanced optical modulation format and code method does improve the system performance by minimizing the effect of some of the degradation sources. In general, the choice of an optimum optical modulation format depends on many factors - such as the fiber type, the data rate per channel, the wavelength spacing, and so on. In this paper we present the results of our investigation into different WDM fiber optical systems, along with our simulation estimates of different optical modulation formats and their impact on the system performance.

\section{EVALUATION OF DIFFERENT MODULATION FORMATS FOR WDM SYSTEMS}

As was mentioned above, the NRZ has long been the dominant code format in IMDD fiber optical communication systems. The major reasons for using this format in the early stage were a relatively low electrical bandwidth for the transmitters and receivers compared with the return-to-zero (RZ) code, and its insensitivity to the laser phase noise compared with the phase shift keying (PSK) [4]. In recent years, the NRZ code format might not be the best choice for high capacity optical systems. However, due to its simplicity and historic dominance, NRZ can be used as a good solution for $10 \mathrm{Gbit} / \mathrm{s}$ WDM systems, because it has the most 
compact spectrum compared with those for other modulation formats [5]. However, this does not mean that an NRZ optical signal has the superior resistance to residual chromatic dispersion in an amplified fiber system with dispersion compensation. Besides, the NRZ coded optical signal has been found to be less resistive to fiber nonlinear effects as compared with other formats.

The RZ code format is relatively insensitive to the fiber nonlinearities and polarization mode dispersion in comparison with the NRZ format. Despite these advantages, a conventional RZ signal is not suited well enough for the use in dense DWDM systems due to its large spectral width. This problem could be solved by using the Duobinary signal, since it has a compact spectrum and a high nonlinear tolerance [6].

Recent studies have indicated that spectral efficiencies well in excess of $1 \mathrm{bit} / \mathrm{s}-\mathrm{Hz}$ should be achievable in WDM systems. However, the use of binary modulation techniques, such as NRZ and RZ on-off keying, limits the spectral efficiency to a maximum of $1 \mathrm{bit} / \mathrm{s}-\mathrm{Hz}$; in turn, guard bands reduce the maximum spectral efficiency below $1 \mathrm{bit} / \mathrm{s}-\mathrm{Hz}$. Next generation commercial DWDM systems are expected to use $40 \mathrm{Gbit} / \mathrm{s}$ channels with a $100 \mathrm{GHz}$ channel spacing corresponding to the spectral efficiency of only $0.4 \mathrm{bit} / \mathrm{s}-\mathrm{Hz}$. Systems of the kind require non-binary encoding techniques, such as multi-level intensity or phase modulation, to exceed the ultimate spectral efficiency limit [7].

By encoding the multiple bits per symbol, non-binary modulation techniques can reach significant spectral efficiency. The spectral narrowing alone can also reduce the effect of chromatic dispersion $(\mathrm{CD})$. Encoding the multiple bits per symbol also gives rise to longer symbol duration, which can, in turn, increase the robustness to fiber propagation impairments by allowing a greater amount of uncompensated CD and PMD to be accumulated before a significant inter-symbol interference (ISI) arises.

The Duobinary coding is the simplest of a large code family (called "partial response" codes). Duobinary is a three-level code which substantially reduces the bandwidth occupancy of a signal compared with NRZ coding. This code is in use in some high-speed long-distance systems because of its spectrum narrowing properties. However, this technique requires highly linear electrical amplifiers for the amplification of three-level signals, a precisely balanced dual-arm modulator, and accurate synchronization between the data modulator and the pulse carver [7].

With optical intensity modulation, a digital signal is represented by random optical power levels. Similarly, a digital signal can also be represented by the phase of an optical carrier, and this is commonly referred to as the optical phase shift key (PSK). In the early days of optical communications, because of the immaturity of semiconductor laser sources, the optical phase was not stable enough for phasebased modulation schemes. In recent years, with the rapid improvement of single frequency laser sources and the application of active phase locking, PSK becomes feasible in practical optical systems. Specifically, the differential phase shift key (DPSK) is the most often used format [8].

\section{SIMULATION SCHEME AND MEASUREMENT TECHNIQUES}

In this section, the generation principles and main characteristics of different modulation formats are explained. 
Our research is based on the evaluation of such an important system parameter as the bit error rate (BER) using powerful techniques incorporated in the OptSim 4.7 simulation software. In the present work, we show the spectrum and eye diagrams for various simulation setups, since they are a fast way to approximately evaluate a system's performance; respectively, an eye has to be open wide enough, and spectrum diagrams should be regular, without a negative multi-peak structure for good system performance. An eye diagram shows the patterns of an electrical signal after detection. The eye height is an indicator of noise, whereas the signal width at the centre of an eye diagram represents a measure of timing jitter [9].

The accepted method of calculation is based on solving a complex set of differential equations, taking into account optical and electrical noise as well as linear and nonlinear effects. We have used a model where signals are propagating as time domain samples over a selectable bandwidth (in our case, a bandwidth that contains all channels). The time domain split step (TDSS) method was employed to simulate linear and nonlinear behavior for both optical and electrical components. The split step method is now used in all commercial simulation tools to perform the integration of a fiber propagation equation that can be written as

$$
\frac{\partial A(t, z)}{\partial z}=\{L+N\} A(t, z) .
$$

Here $A(t, z)$ is the optical field,

$L \quad$ is the linear operator that stands for dispersion and other linear effects,

$N \quad$ is the operator that is responsible for all nonlinear effects.

The idea is to calculate the equation over small spans of fiber $\Delta z$ by including either a linear or a nonlinear operator. For instance, on the first span $\Delta z$ only linear effects are considered, on the second - only nonlinear, on the third again only linear ones, and so on. Two ways of calculation are possible: frequency domain split step (FDSS) and the above mentioned time domain split step (TDSS) methods. These methods differ in how linear operator $L$ is calculated: FDSS does it in a frequency domain, whereas TDSS - in the time domain, by calculating the convolution product in sampled time. The first method is easy to fulfill, but it may produce severe errors during computation. In our simulation we have employed the second method, TDSS, which, despite its complexity, ensures an effective and time-efficient solution [8].

A large number of publications in the world are devoted to modulation formats and code methods, starting from the elaboration of novel efficient numerical methods and ending with the creation of complex DPSK high-speed WDM systems. The aim of our simulation was to compare different modulation formats and to find the most flexible solution for future WDM transmission systems. In particular, the optical power spectrum and the spectral bandwidth of different signals are investigated at the multiplexer/demultiplexer output/input ports. In the next section, the results, together with dispersion and nonlinear effects, will be compared for the system performance of optical networks using conventional NRZ and RZ modulation formats. 
Our simulation scheme consists of three main sections: a transmitter section, a receiver section and the fiber itself (Fig. 1). Such a configuration is common for most fiber optical communication links, because, first of all, it is necessary to prepare the incoming bit stream for propagation via optical fiber; then we have to configure the fiber, and, finally, the signal has to be correctly detected at the end.

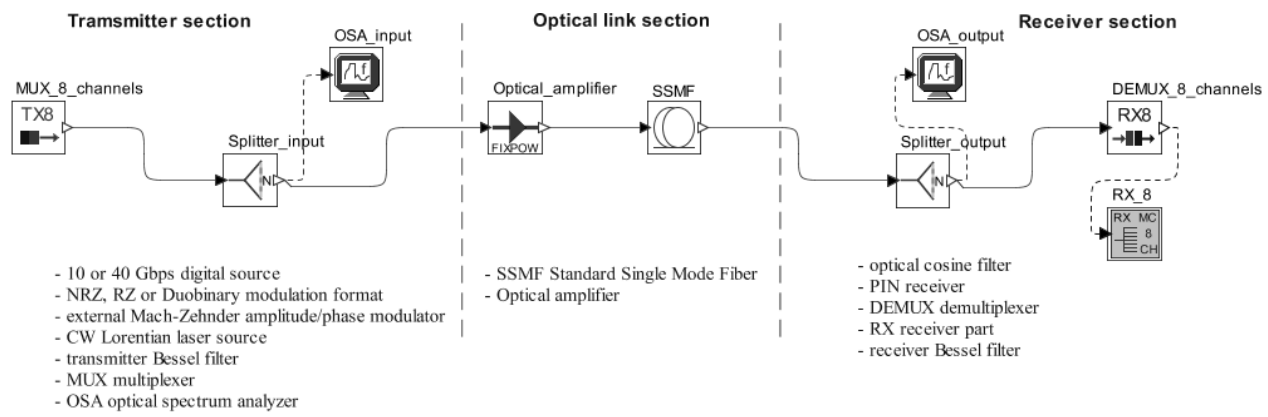

Fig. 1. WDM transmission scheme with 8 equally spaced channels for 10 or $40 \mathrm{Gbit} / \mathrm{s}$ systems with Standard SMF.

a) Simple IMDD NRZ or RZ transmitter realization

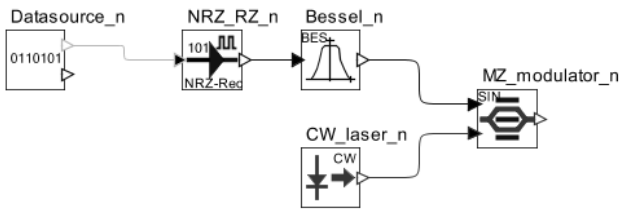

b) Simple IMDD Duobinary NRZ or RZ transmitter realization

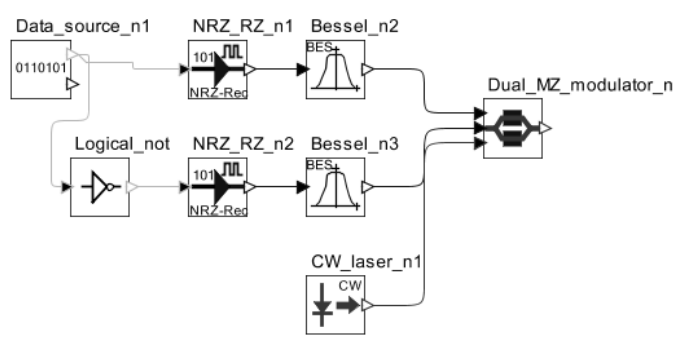

c) Phase modulation NRZ or RZ transmitter realization

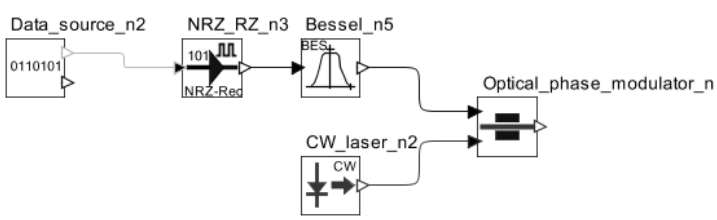

Simple IMDD NRZ or RZ receiver realization

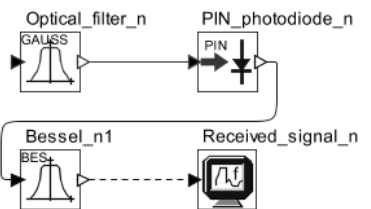

Simple IMDD Duobinary NRZ or RZ receiver realization

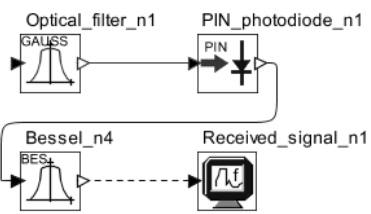

Phase modulation NRZ or RZ transmitter realization

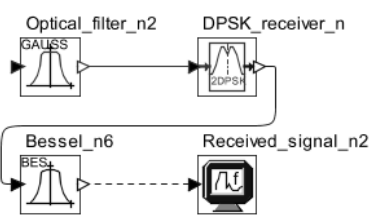

Fig. 2. Block diagrams of various transmitter and receiver modifications for different modulation formats.

A transmitter block contains 8 multiplexed channels, each of them consisting of a data source, a driver, a laser and an external modulator. The data source produces a bit stream that presents the information to be transmitted via the fiber 
optical link. Then the driver forms different code pulses from incoming bits. After that, the pulses are modulated with continuous wave $(\mathrm{CW})$ laser radiation to obtain optical pulses. Such a way of modulation is called amplitude modulation, since the information is presented here by changes in the signal amplitude. Another way of modulation - the optical signal phase modulation or differential phase shift keying (DPSK) - is also possible. Figure 2 depicts different transmitter and receiver realizations. For a DPSK modulation format the optical power is constant, with, howe$v e r$, the phase shifts between " 0 " and " $\pi$ ", and the average optical field being zero. As a consequence, there is no carrier component in the optical field spectrum. This differs from the spectrum of an IMDD system, where the carrier component is strong $[4,9-16]$.

After the transmission block the signal is sent directly to a standard singlemode fiber (SSMF), where optical pulses are propagating over different distances, and the idea is to compare the system performance using various fiber lengths. The used fiber had a large core effective area of $80 \mu \mathrm{m}^{2}$, other parameters being: attenuation $\alpha=0.2 \mathrm{~dB} / \mathrm{km}$, dispersion $D=16 \mathrm{ps} / \mathrm{nm} \cdot \mathrm{km}$, dispersion slope $D_{s l}=$ $=0.07 \mathrm{ps} / \mathrm{nm}^{2} \cdot \mathrm{km}$, and nonlinear refractive coefficient $n_{k}=2.5 \cdot 10^{-20} \mathrm{~cm} / \mathrm{W}$ at the reference wavelength $\lambda=1550 \mathrm{~nm}$. At the fiber end the channels were demultiplexed, so that each channel could be analyzed separately. After that, each channel was optically filtered, converted to an electrical one and then electrically filtered. To evaluate the system performance several measurements were taken. We were interested in observing the optical spectrum at the beginning and at the end of an optical link, as well as in the quality of eye diagrams and bit error rates (BERs) [9, $13-16]$.

\section{RESULTS AND DISCUSSION}

In this section, we present the results of our study, focusing on the comparison of the optical system performance for different modulation formats and standard SMF. In addition to the computer simulation, we also provide our explanation as to the main results and try to outline the physical mechanism underlying our conclusions.

The eye-pattern is a powerful - though simple - time-domain tool for assessing the data capability of an optical digital transmission system. The eyepattern measurements are made in the time domain showing in real time the effects of waveform distortions immediately on an oscilloscope; from an eye-pattern display much information on the system performance can be deduced. The information regarding the signal amplitude distortion, timing jitter and system rise time can be derived simply by observing certain features of the pattern. The eyepattern derived from our simulations will be analyzed to obtain and compare various system performance characteristics.

The fundamental limitation on the speed of communication systems over the embedded standard SMF is linear chromatic dispersion. Figure 3 shows IMDDNRZ format spectra and different eye-patterns after a signal's propagating through fibers of various lengths for $10 \mathrm{Gbit} / \mathrm{s}$ WDM communication systems, with different channel intervals. Also, Fig. 3 shows that, despite the fact that the signal out- 
put value is about $10 \mathrm{dBm}$ lower than at the input, the system is highly efficient. Such great BER values imply that the receiver is not affected by decrease in the signal power caused by the attenuation of optical fiber and passive elements. The choice of arbitrary units that are used on the Y-axis in the eye diagrams was purposeful - to make them more general in the cases when the plotted electrical quantity is current or voltage. The obtained eye-patterns show that when the optical fiber is $90 \mathrm{~km}$ long a system's performance is below the minimum level - that is, the system is out of operation.

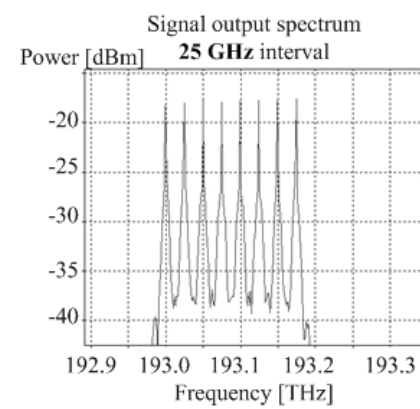

193.0 THz center frequency

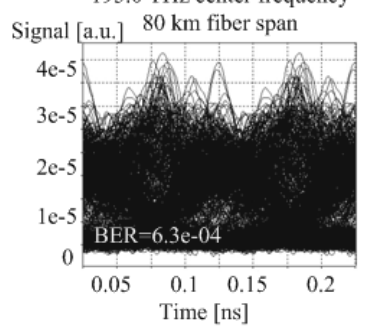

$\begin{array}{cccc}0.05 & 0.1 & 0.15 & 0.2 \\ & \text { Time [ns] } & \\ & & \end{array}$

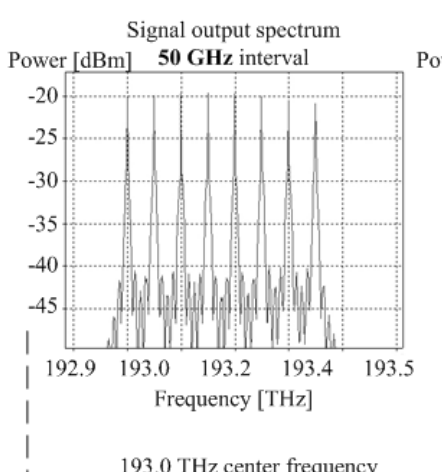

193.0 THz center frequency

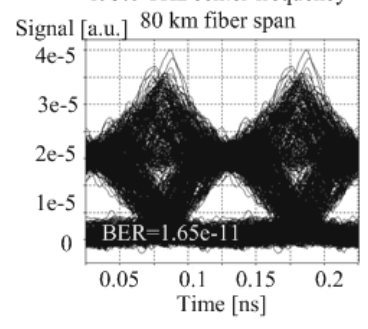

193.0 THz center frequency Signal [a.u.] $90 \mathrm{~km}$ fiber span

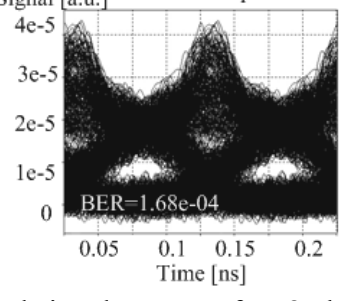

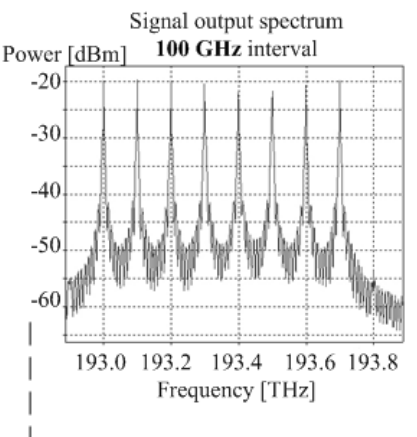

193.0 THz center frequency

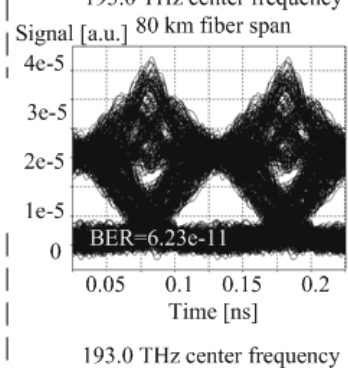

$193.0 \mathrm{THz}$ center frequency
ISignal [a.u.] $90 \mathrm{~km}$ fiber span

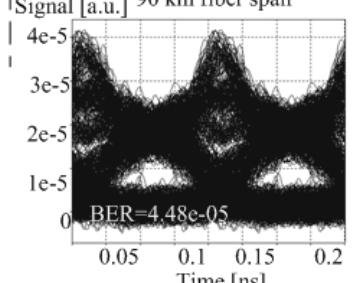

Fig. 3. IMDD-NRZ output optical signal spectra of an 8-channel $10 \mathrm{Gbit} / \mathrm{s}$ WDM system $(25 / 50 / 100 \mathrm{GHz}$ channel spacing) and the output eye diagrams.

When comparing the output eye diagrams, it could be seen that the $25 \mathrm{GHz}$ channel spacing is not suitable for $10 \mathrm{Gbit} / \mathrm{s}$ NRZ modulation format, respectively a $50 \mathrm{GHz}$ channel interval provides better system characteristics. At increasing the channel spacing from $50 \mathrm{GHz}$ to $100 \mathrm{GHz}$ the system performance remains unchanged, so the regeneration site should be located after $85 \mathrm{~km}$.

Figure 4 presents IMDD NRZ format spectra and different eye-patterns for $40 \mathrm{Gbit} / \mathrm{s}$ WDM communication systems, with different channel intervals presented.

This example shows that the optimal channel spacing (which will ensure a sufficient BER) should be greater than $200 \mathrm{GHz}$, and in this case the maximum 
transmission distance would lay somewhere between 3 and $4 \mathrm{~km}$. With channel interval decreasing the system characteristics become unstable, however, the installation of an extra dispersion compensation unit (DCU) and an amplification module would help a $40 \mathrm{Gbit} / \mathrm{s}$ system achieve a $50 \mathrm{~km}$ regeneration length.
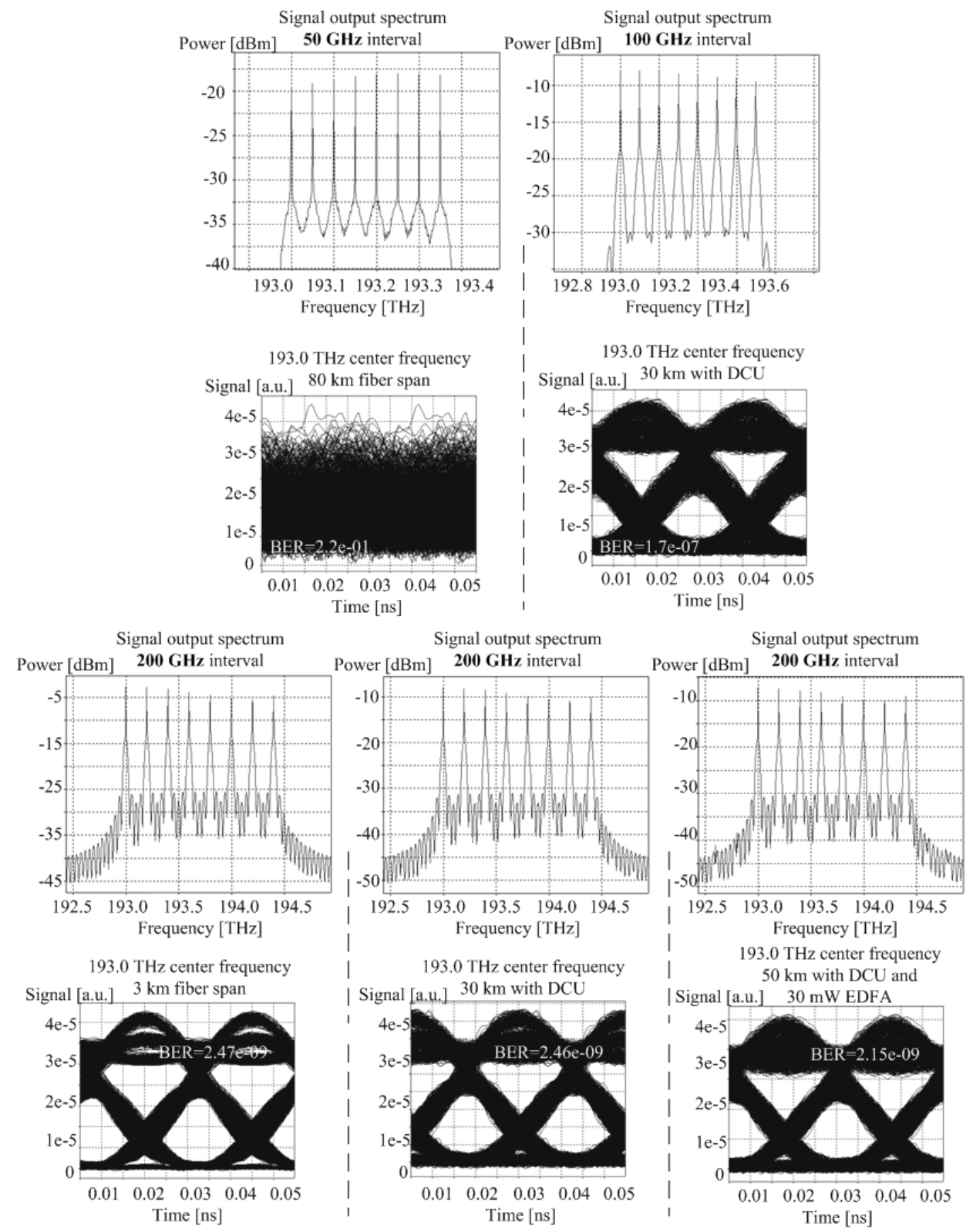

Fig. 4. IMDD-NRZ output optical signal spectra of an 8-channel $40 \mathrm{Gbit} / \mathrm{s}$ WDM system (50/100/200 GHz channel spacing) and the output eye diagrams with dispersion compensation and optical amplification technique.

For the IMDD-RZ modulation format the transmission distances, using the same $10 \mathrm{Gbit} / \mathrm{s}$ transmission technique, are even shorter. Figure 5 shows IMDD-RZ format spectra and different eye-patterns after signal propagating through fibers of 
various lengths for $10 \mathrm{Gbit} / \mathrm{s}$ WDM communication systems, where different channel intervals are presented.

Comparing the output eye diagrams, one can see that the $50 \mathrm{GHz}$ channel spacing is not suitable for the $10 \mathrm{Gbit} / \mathrm{s} \mathrm{RZ}$ modulation format, whereas the $100 \mathrm{GHz}$ channel interval provides better system characteristics. When the channel spacing is increased from $100 \mathrm{GHz}$ to $200 \mathrm{GHz}$, the system performance remains the same, and the regeneration site is to be located after $40 \mathrm{~km}$, which is twice as short as in the NRZ modulation format case.
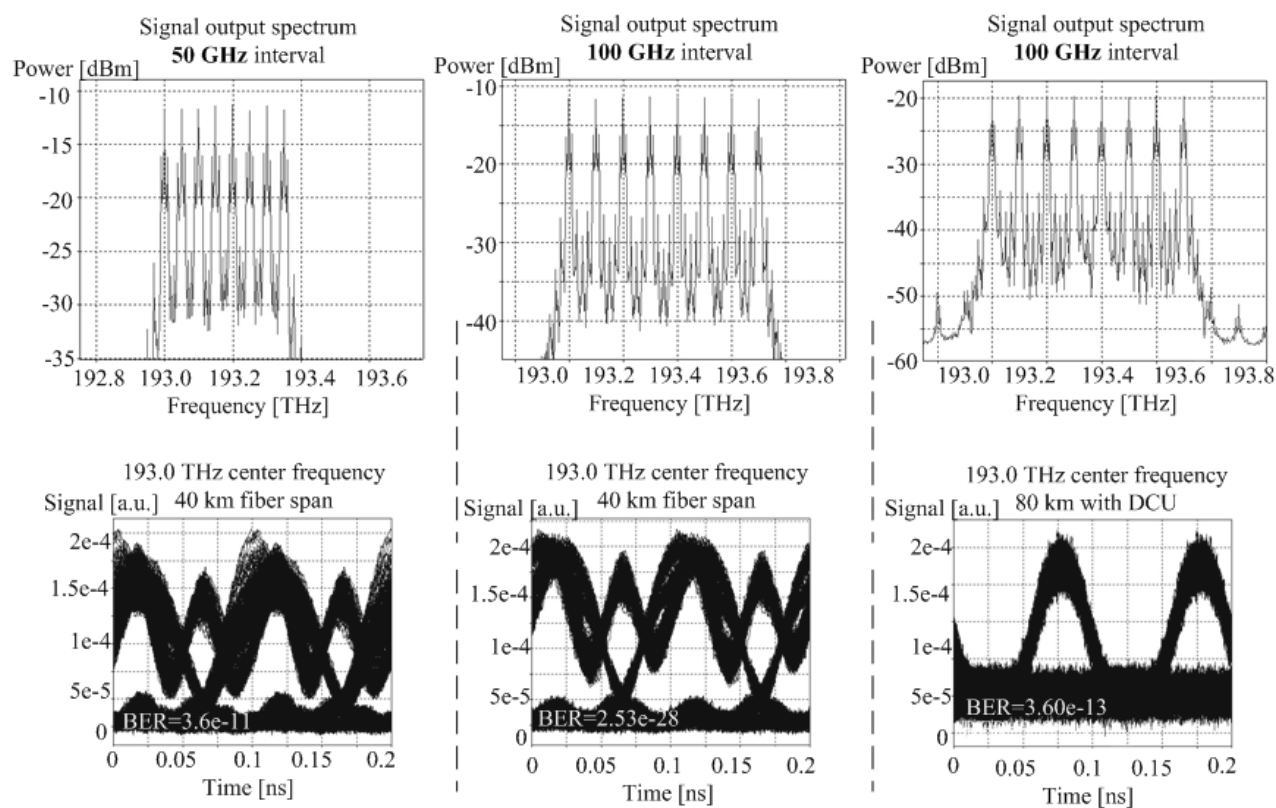

| Signal [a.u.] $40 \mathrm{~km}$ fiber span
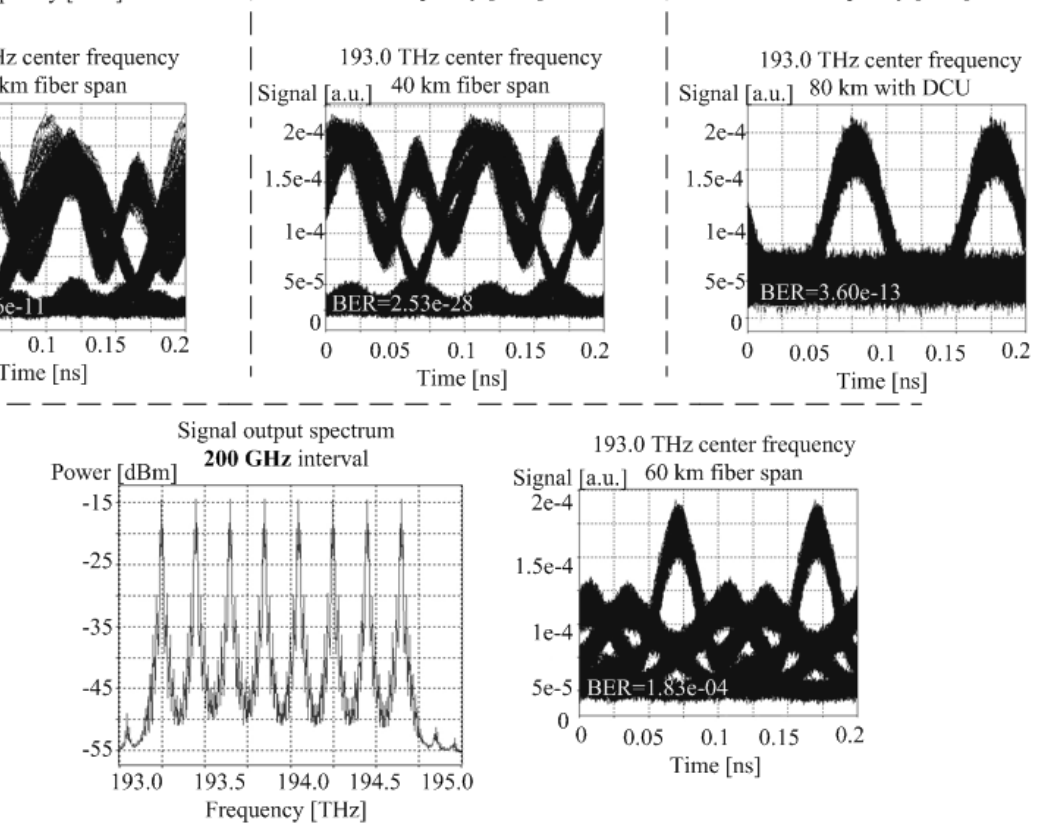

193.0 THz center frequency

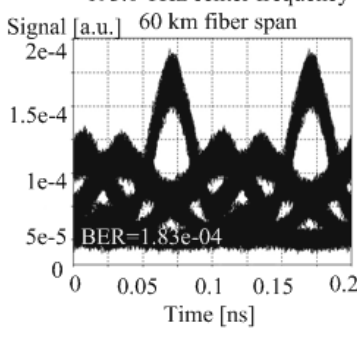

Fig.5. IMDD-RZ output optical signal spectra of an 8-channel $10 \mathrm{Gbit} / \mathrm{s}$ WDM system (with 50/100/200 GHz channel spacing) and the output eye diagrams.

Figure 6 presents IMDD-RZ format spectra and different eye-patterns for $40 \mathrm{Gbit} / \mathrm{s}$ WDM communication systems, where the optimal $100 \mathrm{GHz}$ channel interval is investigated.

Similar to the above examples, here an optimal channel spacing that ensures a sufficient BER should be greater than $100 \mathrm{GHz}$, and in this case the maximum transmission distance would be in the range $6-8 \mathrm{~km}$, which is two times greater than in the NRZ modulation case. At the channel interval decreasing there appear unstable system characteristics. To improve the situation, an extra dis- 
persion compensation unit (DCU) and an amplification module could be installed, so that the system can achieve a $170 \mathrm{~km}$ regeneration length. Our numerical simulation shows that the IMDD-RZ modulation format is more resistant to dispersion and NOE in $40 \mathrm{Gbit} / \mathrm{s}$ systems as compared with IMDD-NRZ formats.
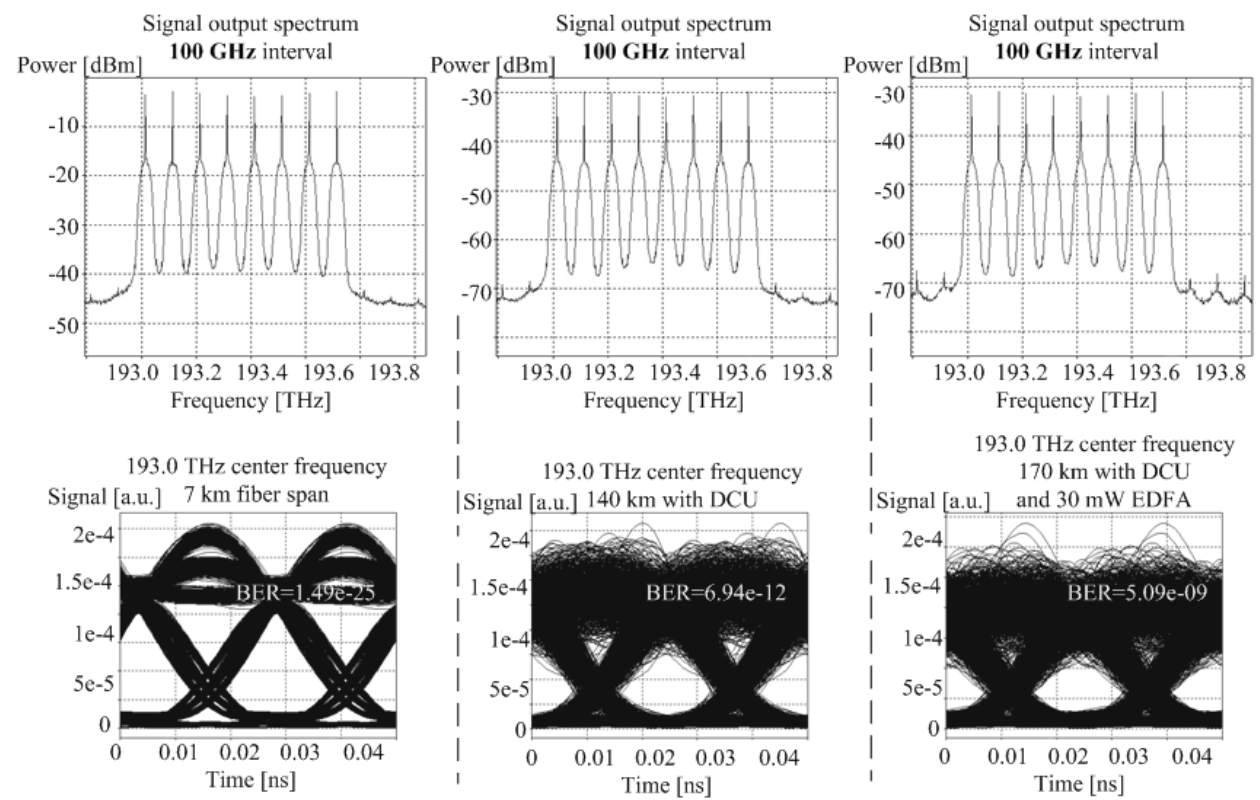

Fig. 6. IMDD-RZ output optical signal spectra of an 8-channel $40 \mathrm{Gbit} / \mathrm{s}$ WDM system (with $100 \mathrm{GHz}$ channel spacing) and output eye diagrams with dispersion compensation unit and optical amplification technique.
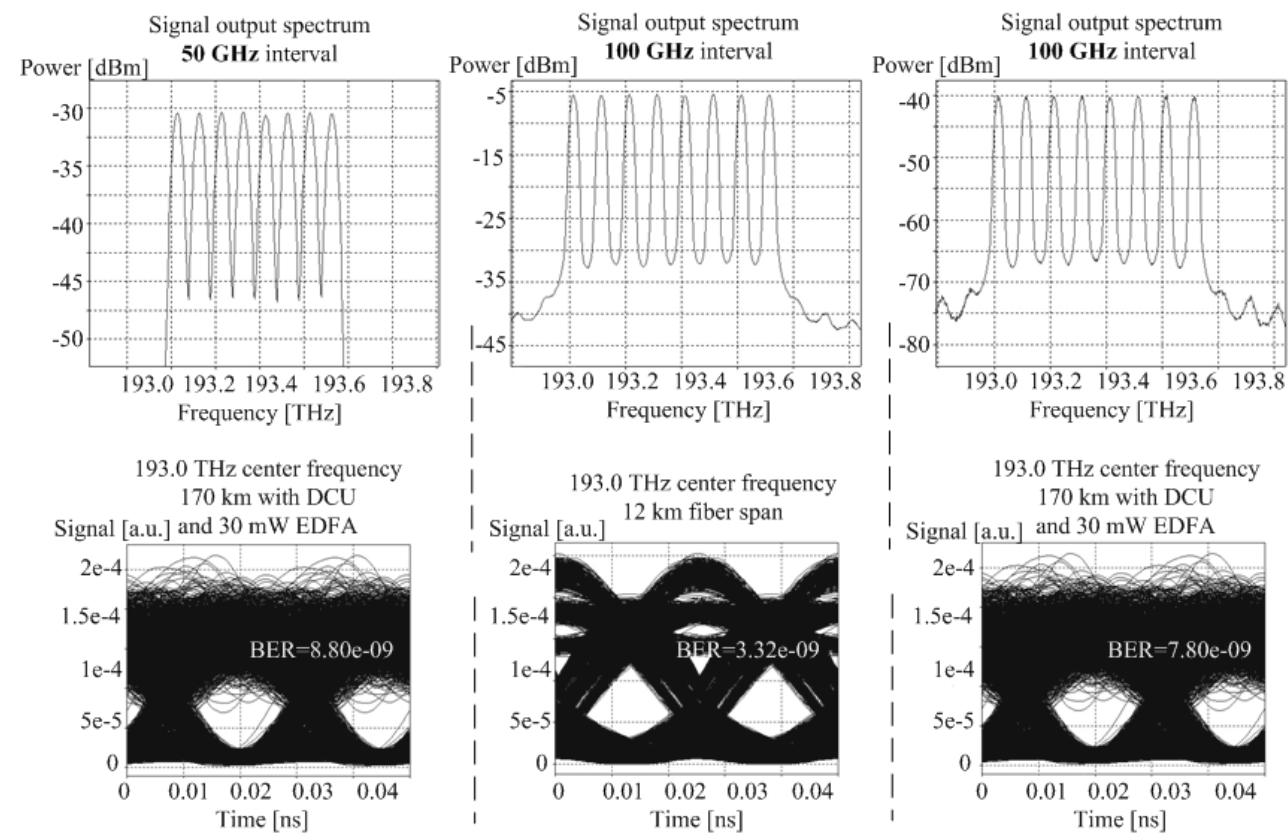

Fig. 7. IMDD Duobinary output optical signal spectra of an 8-channel $40 \mathrm{Gbit} / \mathrm{s}$ WDM system (with 50/100 GHz channel spacing) and the output eye diagrams with dispersion compensation and optical amplification technique. 
Figure 7 shows the IMDD Duobinary format spectra and different eyepatterns after signal propagating through fibers of various lengths for $40 \mathrm{Gbit} / \mathrm{s}$ WDM communication systems. The $100 \mathrm{GHz}$ and $50 \mathrm{GHz}$ channel intervals presented are optimal.

An optimal channel spacing (which will guarantee a sufficient BER) for IMDD Duobinary should here be greater than $100 \mathrm{GHz}$, in this case the maximum transmission distance would be between 12 and $14 \mathrm{~km}$, which is four times greater than in the NRZ modulation case.

An increase in the channel number can be achieved either by raising the bandwidth (and preserving the same channel spacing) or by decreasing the channel spacing (thus keeping the bandwidth as narrow as possible). Each method has its advantages and drawbacks, because we are usually interested both in narrowing the bandwidth and reducing the crosstalk between channels. In our simulation we have chosen to reduce the channel spacing from $100 \mathrm{GHz}$ to $50 \mathrm{GHz}$. It has turned out that reducing the channel spacing means stricter requirements to be imposed on the system characteristics. At the same time, the channel interval decreasing leads to stable system characteristics, and an extra dispersion compensation unit (DCU) and amplification module would provide for the system a $170 \mathrm{~km}$ regeneration length.

Comparing NRZ, RZ and Duobinary spectra, it can be seen that the last of them has a slightly more open eye. This means easier and more accurate signal detection in the system. Numerical simulation has shown that the Duobinary modulation format supports the system's performance much better since it better alleviates the effect of fiber nonlinearities than conventional RZ and NRZ.

Finally, we will show the system performance when the DPSK modulation technique is used. Intuitively, DPSK modulated signals have a constant optical power and the system's performance is not affected by nonlinear effects (such as SPM and XPM) stemming from optical power modulation. As distinct from the above figures (Figs. 3-7), Fig. 8 shows DPSK format spectra and different eyepatterns after signal propagating over fibers of various lengths for $40 \mathrm{Gbit} / \mathrm{s}$ WDM communication systems, with different channel spacing.

In $40 \mathrm{Gbit} / \mathrm{s}$ optical systems, SPM is one of the major contributors to the system performance degradation. The effect of SPM is the strongest for standard SMF, which has the highest local chromatic dispersion. It is noticed that both NRZ and RZ are intensity-modulation-based optical systems and therefore the SPM originates from the signal intensity modulation. Intuitively, the optical systems based on the optical phase modulation would significantly reduce the effect of SPM because the optical power is not modulated.

The optimal channel spacing (which will ensure a sufficient BER) that could be inferred from this example should be greater than $75 \mathrm{GHz}$. As in previous cases, installation of extra dispersion compensation unit (DCU) and amplification module would increase the system's regeneration length - in this case over $180 \mathrm{~km}$. Our numerical simulation shows superior characteristics of the DPSK modulation format for $40 \mathrm{Gbit} / \mathrm{s}$ WDM transmission systems. 

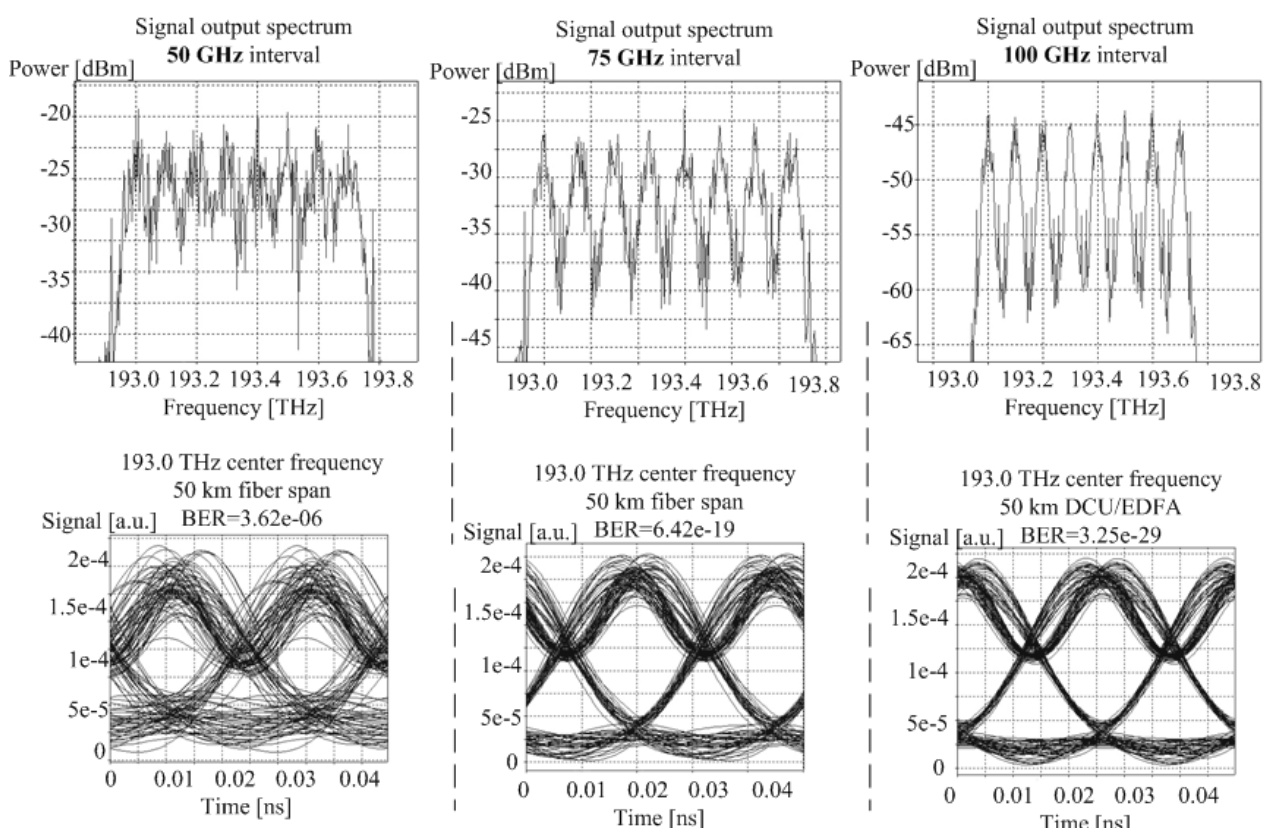

Signal [a.u.] BER=6.42e-19
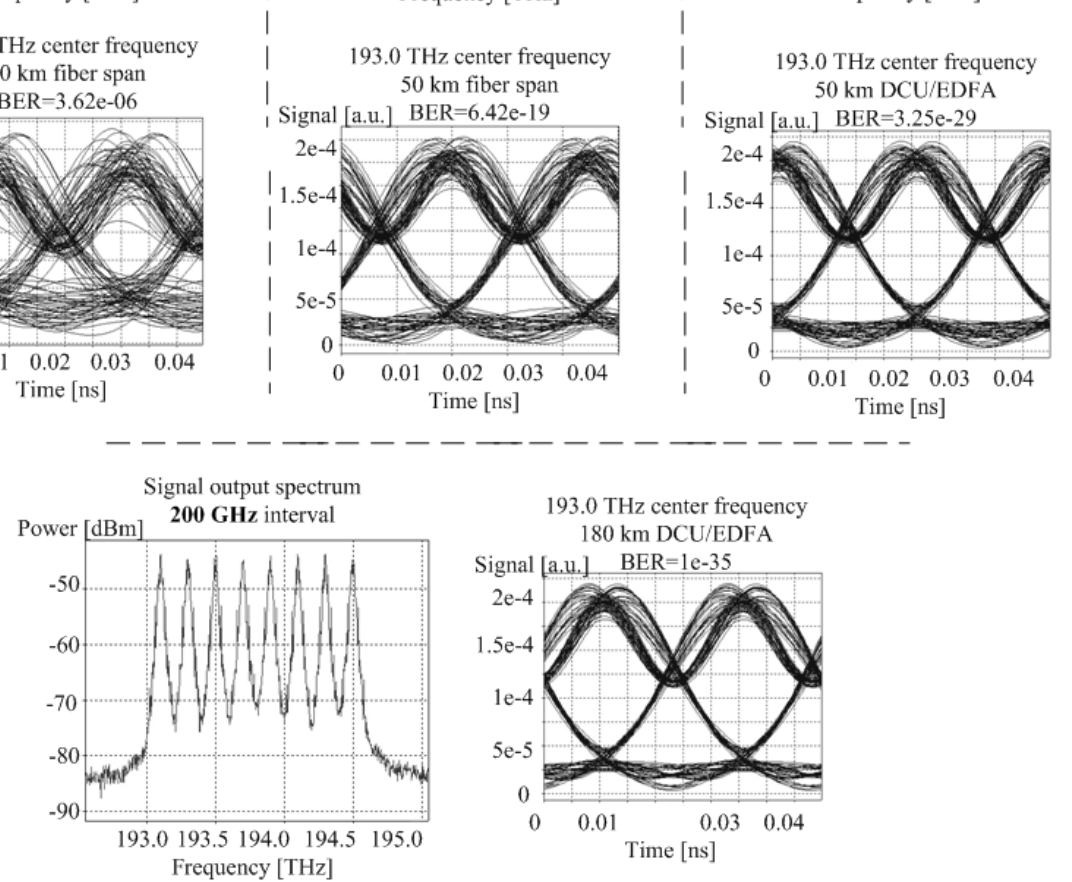

Fig.8. DPSK output optical signal spectra of an 8-channel $40 \mathrm{Gbit} / \mathrm{s}$ WDM system (with 50/75/100/200 GHz channel spacing) and the output eye diagrams with dispersion compensation and optical amplification technique.

\section{CONCLUSIONS}

In this work we have investigated the performance of $10 \mathrm{Gbit} / \mathrm{s}$ and $40 \mathrm{Gbit} / \mathrm{s}$ optical systems with various optical modulation formats and a standard singlemode fiber. For WDM systems with narrow channel spacing, nonlinear crosstalks originated from XPM and FWM are major sources of system performance degradation. A standard SMF was selected for our simulations deliberately, because currently installed fibers are mostly single-mode, so for direct investigation of different modulation formats the former is more suitable. Our research was concentrated on $40 \mathrm{Gbit} / \mathrm{s}$ schemes where different channel intervals were presented and it was found that for optical systems with $100 \mathrm{GHz}$ channel spacing the SPM could be identified as the major source of performance degradation if IMDD-NRZ or RZ modulation formats were used. The SPM effect can be reduced to some extent by using advanced modulation formats and optical phase modulation providing the optimum suppression of this effect because in this case there is no intensity modulation. Since the mentioned effect is strong in fibers with high local dispersion, its 
effective reduction will be a key for practical application of $40 \mathrm{Gbit} / \mathrm{s}$ optical transmissions in standard-SMF-based fiber spans.

It has been shown that the BER and eye-diagram technique is a good means for evaluating the system performance that allows a WDM system to be optimized for different parameters.

The main conclusions of our simulation are therefore as follows.

- The dispersion-limited distance for conventional NRZ external modulated systems at $10 \mathrm{Gbit} / \mathrm{s}$ and $40 \mathrm{Gbit} / \mathrm{s}$ is about $80 \mathrm{~km}$ and $4 \mathrm{~km}$, respectively. For the RZ format these distances are even shorter, but with the use of DCU and amplification technique these lengths can be substantially increased.

- The NRZ and Duobinary modulation formats have similar transmission properties and are equally efficient for short traces. For long traces Duobinary modulation is a much more resilient modulation scheme in the presence of chromatic dispersion, and it is possible to extend the reach of conventional systems from $80 \mathrm{~km}$ to $170 \mathrm{~km}$.

- Comparison of NRZ, RZ and Duobinary formats shows a slightly more open eye for the last one, which provides easier and more accurate signal detection in this system. Our numerical simulation has shown that the Duobinary modulation format provides much more perfect system performance since it better alleviates the effect of fiber nonlinearities than conventional RZ and NRZ formats.

- In $40 \mathrm{Gbit} / \mathrm{s}$ optical systems, SPM in the transmission fiber becomes the major source of performance degradation, which makes a standard SMF vulnerable because of its high dispersion. In order to make such SSMFs more competitive for $40 \mathrm{Gbit} / \mathrm{s}$ optical transmissions, optical phase modulation must be used.

- Duobinary and DPSK modulation formats are shown to be highly suitable for ultra-high spectral efficient WDM systems and highly resilient to dispersion and NOEs.

\section{REFERENCES}

1. Agrawal, G. (2001). Nonlinear Fiber Optics ( $3^{\text {rd }}$ edn). Academic Press.

2. Kurmer, N., \& Shen, Y.R. (1999). The Principles of Nonlinear Optics. New York etc.: John Wiley \& Sons.

3. Keiser, G. (2004). Optical Fiber Communications. New York etc.: Mc. Graw-Hill.

4. Le Nguyen, B., \& Zsiofia, C. (2003). DSCS RZ and NRZ modulation formats for high capacity optical communications systems. Technical report. 3, 1-18.

5. Fukuchi, K. (2002). Wideband and Ultra-Dense WDM Transmission Technologies Toward over 10 Tbit/s Capacity. In Optical Fiber Communications Conference (Anaheim).

6. Vitesse, S. (2004). NRZ and Duobinary Compatibility. Lucent Technol. (1), 27-29.

7. Bobrovs, V., \& Ivanovs, G. (2007) Investigation of Advanced Modulation Formats for $40 \mathrm{Gbit} / \mathrm{s}$ communication systems. Latvian RTU Collection. (2), 12-14.

8. OptSim 4.7 User Guide http://www.rsoftdesign.com/.

9. Leibrich, J., \& Rosenkranz, W. (2002). Efficient numerical simulation of multichannel WDM transmission systems limited by XPM. IEEE Photon. Techno. Letters. (2), 2836. 
10. Porins, J., Ozols, A., \& Ivanovs, G. (2004). Nonlinear Optical Losses in Telecommunication Fibers. Latv. J. Phys. Tech. Sci. (3), 48-58.

11. Bouteiller, J., \& Leng, L. (2004). Pump-pump four-wave mixing in distributed Raman amplified systems. J. Lightwave Technol. 22 (3), 723-732.

12. Humblet, P., \& Azuzoglu, M. (1991). On the bit error rate of lightwave systems with optical amplifiers. J. Lightwave Technol. 9 (11) 1576-1582.

13. Renxiang, H. (2001). Simulation and Experimental Study of WDM Optical Systems. Technical report. 1, 28-44.

14. Bobrovs, V., Makovejs, S., Porins, J., \& Ivanovs, G. (2007). Demonstration and analysis of dual nature of stimulated Raman scattering in fiber optical communication systems. Latv. J. Phys. Tech. Sci. (1), 34-50.

15. Bobrovs, V., \& Ivanovs, G. (2006). Parameter evaluation of a dense optical network. Lithuanian Journal of Electronics and Electrical Engineering. (4), 33-37.

16. Bobrovs, V., Porins, J., \& Ivanovs G. (2007) Influence of nonlinear optical effects on the NRZ and RZ modulation signals in WDM systems. Lithuanian Journal of Electronics and Electrical Engineering. (4), 31-34.

\title{
DAŽĀDU VEIDU MODULĀCIJAS FORMĀTU SALĪDZINĀŠANA UN IZMANTOŠANAS IESPĒJU IZPĒTE WDM SAKARU SISTĒMĀS
}

\author{
V. Bobrovs, Ģ. Ivanovs \\ Kopsavilku ms
}

Darbā pētîtas un salīdzinātas intensitātes un fāzes modulācijas metodes optiskajās spektrālās blīvēšanas (WDM) sistēmās. Binārie un daudzlīmeṇu kodēšanas formāti ir skaitliski novērtēti ar simulācijas programmatūras OptSim palīdzību pie $10 \mathrm{Gbit} / \mathrm{s}$ un $40 \mathrm{Gbit} / \mathrm{s}$ pārraides ātrumiem, izmantojot garas optiskās šķiedras līnijas un dispersijas kompensēšanas tehniku. Galvenās problēmas, kas ekspluatācijas laikā ir jāṇem vērā sistēmās ar pārraides ātrumu līdz $40 \mathrm{Gbit} / \mathrm{s}$, ir hromatiskā dispersija (CD), polarizācijas - modu dispersija (PMD), dispersijas slīpums un pārraides līnijas nelineārie efekti. Novērtēti perspektīvākie modulācijas formāti $40 \mathrm{Gbit} / \mathrm{s}$ WDM sistēmām. Pētîjumā uzskatāmi demonstrēts, ka daudzlīmeṇu modulācijas un diferenciālās fāzes manipulācijas (DPSK) formāti ir atbilstošākie liela àtruma spektrāli efektīvām sistēmām. Tos var raksturot ar augstu noturības līmeni pret dispersiju un nelineārajiem optiskajiem efektiem (NOE).

25.03.2008. 